\title{
A STUDY ON INFLUENCE OF DIABETES ON SHORT-TERM MORTALITY IN ELDERLY PATIENTS WITH ACUTE MYOCARDIAL INFARCTION
}

\author{
Suresh Kanna $S^{1}$, Karunakaran $N^{2}$
}

${ }^{1}$ Assistant Professor, Department of General Medicine, Sree Balaji Medical College and Hospital, Chromepet, Chennai, Tamilnadu, India. ${ }^{2}$ Assistant Professor, Department of General Medicine, Government Stanley Medical College and Hospital, Chennai, Tamilnadu, India.

\author{
BACKGROUND \\ ABSTRACT \\ Cardiovascular problems are a major cause of mortality in India, causing > 25\% deaths. About 30\% acute coronary syndrome \\ patients had diabetes mellitus and $70 \%$ were above 50 yrs. of age. \\ This study was carried out to know the influence of Diabetes on short-term mortality in Acute Myocardial Infarction in elderly \\ patients.
}

\section{MATERIALS AND METHODS}

This is a prospective observational study conducted in 100 patients in Government Stanley Medical College Hospital, Chennai, over 6 months period. A predefined proforma was completed in every patient with detailed history, physical examination, lab and investigation parameters, interventions and outcome. Persons satisfying the inclusion criteria based on age, definition of acute MI and diabetes mellitus were assessed on the basis of history, clinical examination, ECG changes, cardiac biomarkers and diabetic status. Statistical analysis was done using Epi-Info software and Chi-square test for comparing categorical variables.

\section{RESULTS}

Mean age of study population was $70.26+/ \_13.44$ yrs. Out of 100 patients studied, $93 \%$ had STEMI and 7\% had NSTEMI. Pattern of wall involvement in Myocardial Infarction was almost equal, about 25\% were diabetic. 52 patients presented within 4 hours of onset of symptoms and 7 patients after 12 hours. 73\% patients presented in Killip class-1, 20\% patients in Killip class-2, 5\% patients in class- 3 and $2 \%$ in class- 4 . The in-hospital mortality was $25 \%$ and for diabetics it was $41.67 \%$.

\section{CONCLUSION}

Elderly patients with Acute Myocardial Infarction had a significantly increased chance of in-hospital mortality if they were diabetic.

\section{KEY WORDS}

Diabetes Mellitus, Myocardial Infarction, Elderly, Short-Term Mortality.

HOW TO CITE THIS ARTICLE: Kanna SS, Karunakaran N. A study on influence of diabetes on short-term mortality in elderly patients with acute myocardial infarction. J. Evolution Med. Dent. Sci. 2018;7(39):4299-4303, DOI: 10.14260/jemds/2018/958

\section{BACKGROUND}

Cardiovascular diseases are a major cause of mortality in India, causing $>25 \%$ deaths. Indians develop coronary artery disease at an earlier age. $30.4 \%$ of the acute coronary syndrome patients had diabetes mellitus. $70 \%$ patients were above 50 yrs. of age and $13.3 \%$ above 70 yrs.(1) Diabetes mellitus is associated with vascular endothelial dysfunction and accelerated atherosclerosis. The risk of developing coronary artery disease has increased 2 - 4 fold by developing diabetes.(2) Among persons with CAD, diabetes increases the risk of developing an acute coronary syndrome and of death after an acute myocardial infarction. Elderly patients with acute myocardial infarction fare worse than young patients. The elderly diabetics are at a greater risk of developing myocardial infarction, recurrent myocardial infarction and cardiac dysfunction.

'Financial or Other Competing Interest': None.

Submission 18-06-2018, Peer Review 13-09-2018,

Acceptance 18-09-2018, Published 24-09-2018.

Corresponding Author:

Suresh Kanna $S$,

No. 8A, Vasantham, 2nd Floor,

VOC Street, Nethaji Nagar,

Chromepet, Chennai-600044,

Tamilnadu, India.

E-mail: sureshkannatmc@gmail.com

DOI: $10.14260 /$ jemds $/ 2018 / 958$
Diabetic patients seek medical care late and they are less likely to receive thrombolytic therapy.(3) The in-hospital mortality is higher in diabetic patients in contrast to nondiabetics, as is the 30-day mortality. However, there have not been sufficient studies on the influence of diabetes mellitus in the outcome of acute myocardial infarction in the elderly population.(4)

Objective- To study the influence of Diabetes on short-term mortality (within 30 days of admission) in Acute Myocardial Infarction in elderly patients admitted in Government Stanley Medical College, Chennai.

\section{MATERIALS AND METHODS}

This is a prospective observational study on 100 patients admitted in Intensive Cardiac Care Unit, Cardiac and Medical wards of Government Stanley Medical College, Chennai with acute myocardial infarction over a period of 6 months from March 2015 to August 2015. Sample size was taken conveniently.

\section{Inclusion Criteria}

- Patients of age $\geq 60$ years.

- Acute myocardial infarction as defined below:

For the purpose of this study, Acute Myocardial Infarction was defined as the presence of rise and/or fall of cardiac biomarkers after the index pain with at least one value above 
3 times the normal upper reference limit with at least one of the following.

- Symptoms of ischaemia.

- $\quad$ ECG changes suggestive of new ischaemia.

- Development of pathological Q-waves in the ECG.

- New regional wall motion abnormality on Echocardiography. ${ }^{(5)}$

\section{Exclusion Criteria}

Persons presenting more than 10 days after the onset of symptoms.

\section{Methodology}

For the purpose of this study diabetes was defined as a history of diabetes mellitus, taking drugs for diabetes mellitus or the presence of any one of the-

- Symptoms of diabetes plus random plasma glucose concentration $\geq 200 \mathrm{mg} / \mathrm{dL}$

- $\quad F P G \geq 126 \mathrm{mg} / \mathrm{dL}$

- $\mathrm{HbA1c} \geq 6.5 \%{ }^{(6)}$

Acute myocardial infarction as has been defined above. Persons satisfying the inclusion criteria were assessed on the basis of history, clinical examination, ECG changes, cardiac biomarkers and diabetic status. Patients will be followed up 30 days after discharge. Risk stratification was done using TIMI score, calculated at admission. It was calculated separately for ST elevation and non-ST elevation myocardial infarction. A higher score meant a higher risk of complication and mortality.

\section{Ethical Aspects}

Informed consent was taken from the patient. There were no major ethical issues involved as no invasive procedures were done on patients as part of the study alone. The study did not have financial support from any source and did not cause any financial burden to the patient.

\section{Statistical Analysis}

Statistical analysis was done using Epi-Info Software version 7.1.2.0. Continuous variables were presented as mean values with Standard Deviation. Chi-square test was used for comparing categorical variables. Fisher Exact test was used for variables less than 5 in number to compare categorical data. Where necessary, Odd's ratio was calculated and presented. A probability value of $<0.05$ was considered statistically significant.

\section{RESULTS}

\section{Age Distribution}

Of the 100 patients studied, 91 (91\%) were < 80 years of age. Nine $(9 \%)$ were $\geq 80$ years. The mean age of the study population was $70.26 \pm 13.44$ years. Mean age of patients without diabetes was $70.21 \pm 13.44$ years. Mean age of the diabetic population was $70.42 \pm 13.70$ years.

\section{Gender and Diabetes Mellitus}

64 patients were male and 36 female. 24 (24\%) of them were diabetic. $13(20.31 \%)$ of the males and $11(30.56 \%)$ of the females had diabetes mellitus.

\begin{tabular}{|c|c|c|}
\hline & Diabetic & Non-Diabetic \\
\hline Male & 13 & 51 \\
\hline Female & 11 & 25 \\
\hline \multicolumn{2}{|c|}{ Table 1. Gender and Diabetes Mellitus in Elderly Patients } \\
with Acute MI
\end{tabular}

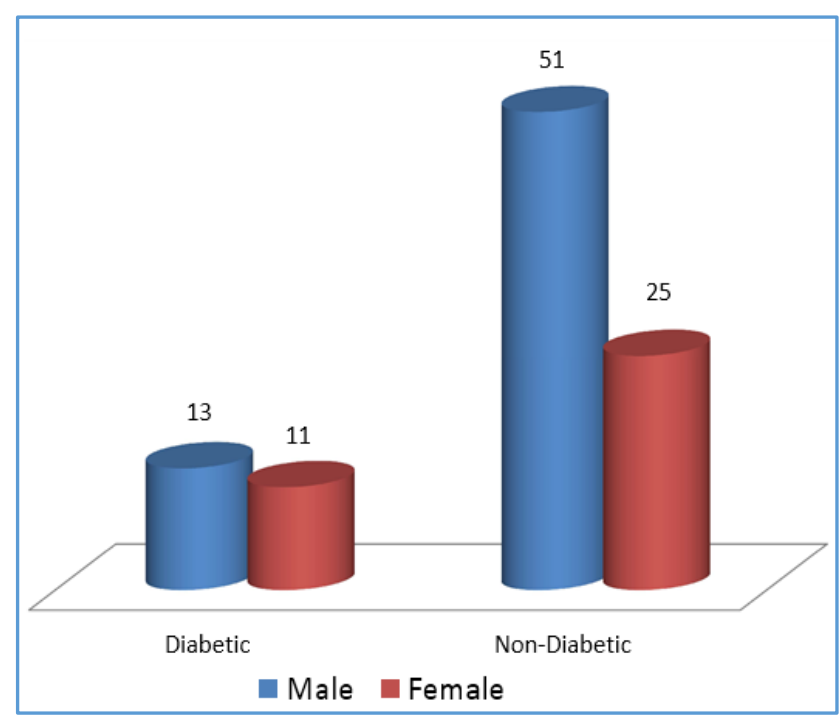

Chart 1. Gender and Diabetes Mellitus in Elderly Patients with Acute MI

Pattern of Wall Involvement in Myocardial Infarction Of the 100 patients studied, 93 (93\%) had ST elevation myocardial infarction and 7 (7\%) had non-ST elevation myocardial infarction. 36 patients presented with anterior wall myocardial infarction, of which 9 were diabetic. Out of 37 patients who had inferior wall myocardial infarction, 9 were diabetic. 17 patients had combined inferior and posterior wall myocardial infarction. 5 of them were diabetic. 1 out of the 9 cases of lateral wall myocardial infarction was diabetic. There was a single case of new-onset left bundle branch block.

\begin{tabular}{|c|c|c|c|c|c|}
\hline $\begin{array}{c}\text { Wall } \\
\text { Involvement }\end{array}$ & $\begin{array}{c}\text { Inferior } \\
\text { Wall }\end{array}$ & $\begin{array}{c}\text { Anterior } \\
\text { Wall }\end{array}$ & $\begin{array}{c}\text { Inferior } \\
\text { +Posterior }\end{array}$ & $\begin{array}{c}\text { Lateral } \\
\text { Wall }\end{array}$ & $\begin{array}{c}\text { New } \\
\text { LBBB }\end{array}$ \\
\hline Frequency & 28 & 27 & 12 & 8 & 1 \\
\hline Percent & $36.84 \%$ & $35.53 \%$ & $15.79 \%$ & $10.53 \%$ & $1.32 \%$ \\
\hline $\begin{array}{c}95 \% \mathrm{CI} \\
\text { Lower }\end{array}$ & $26.06 \%$ & $24.88 \%$ & $8.43 \%$ & $4.66 \%$ & $0.03 \%$ \\
\hline $95 \%$ CI Upper & $48.69 \%$ & $47.34 \%$ & $25.96 \%$ & $19.69 \%$ & $7.11 \%$ \\
\hline Table 2. Pattern of Wall Involvement in Acute MI in Elderly \\
Non-Diabetics \\
\hline
\end{tabular}

\begin{tabular}{|c|c|c|c|c|c|}
\hline $\begin{array}{c}\text { Wall } \\
\text { Involvement }\end{array}$ & $\begin{array}{c}\text { Inferior } \\
\text { Wall }\end{array}$ & $\begin{array}{c}\text { Anterior } \\
\text { Wall }\end{array}$ & $\begin{array}{l}\text { Inferior+ } \\
\text { Posterior }\end{array}$ & $\begin{array}{c}\text { Lateral } \\
\text { Wall }\end{array}$ & $\begin{array}{c}\text { New } \\
\text { LBBB }\end{array}$ \\
\hline Frequency & 9 & 9 & 5 & 1 & 0 \\
\hline Percent & $37.50 \%$ & $37.50 \%$ & $20.83 \%$ & $4.17 \%$ & $0.00 \%$ \\
\hline $95 \%$ CI Lower & $18.80 \%$ & $18.80 \%$ & $7.13 \%$ & $0.11 \%$ & $0.00 \%$ \\
\hline $95 \%$ CI Upper & $59.41 \%$ & $59.41 \%$ & $42.15 \%$ & $21.12 \%$ & $14.25 \%$ \\
\hline Table 3. Pattern of Wall Involvement in Acute MI in Elderly \\
Diabetics \\
\hline
\end{tabular}




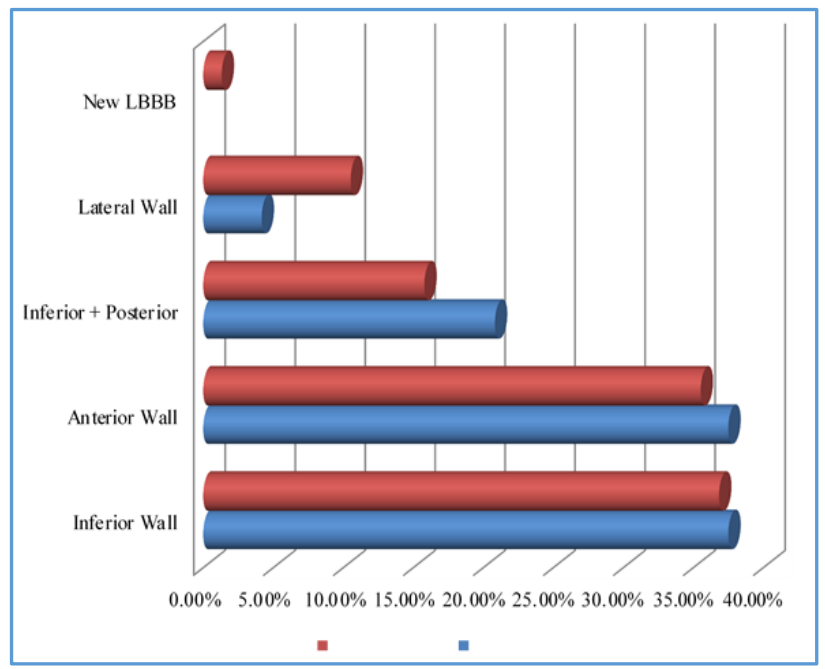

Chart 2. Pattern of Wall Involvement in Acute MI in Elderly Patients

Time for Treatment

52 patients presented within 4 hours of onset of symptoms. $10(19.23 \%)$ of them were diabetic. 41 presented within 4-12 hours of symptom onset. 12 (29.27\%) of them were diabetic. Seven patients presented more than 12 hours after beginning of symptoms. Two of them (28.57\%) were diabetic.

\begin{tabular}{|c|c|c|}
\hline $\begin{array}{c}\text { Time for Treatment in } \\
\text { Hours }\end{array}$ & Diabetic & Non-Diabetic \\
\hline$\leq 4$ & 10 & 42 \\
\hline 4 to12 & 12 & 29 \\
\hline \multicolumn{2}{|c|}{ Table 4. Time for Treatment in Elderly Patients with Acute } \\
MI \\
\hline
\end{tabular}

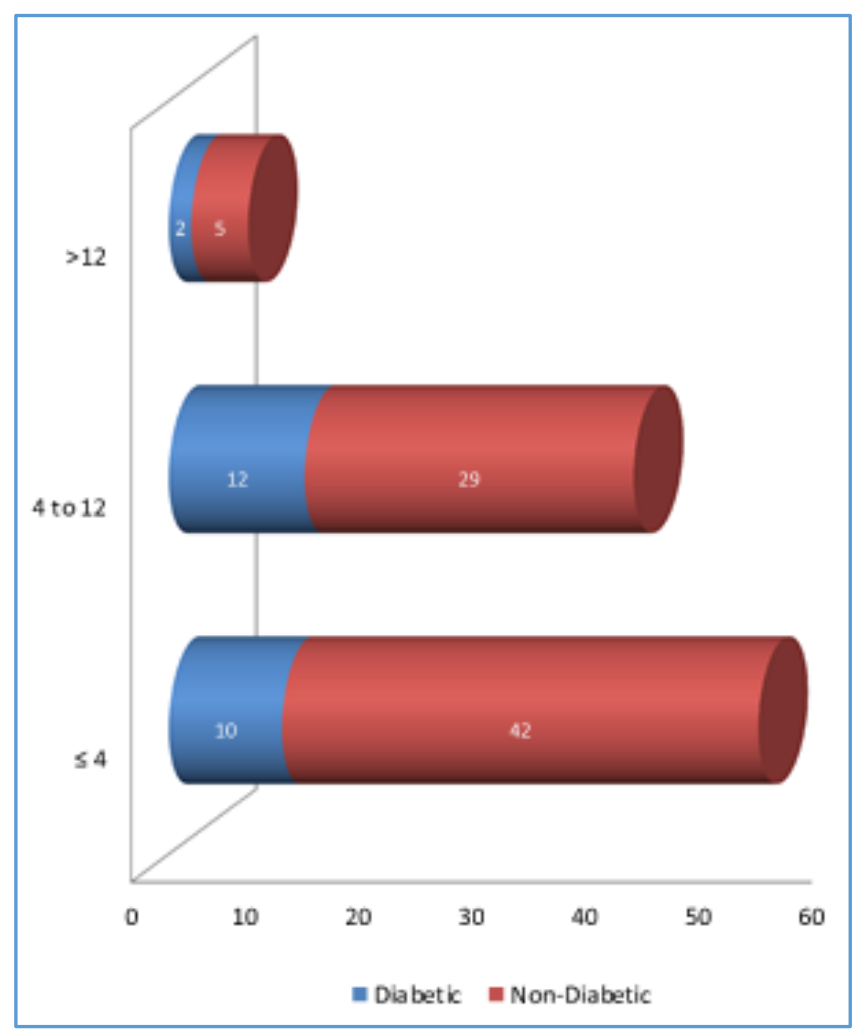

Chart 3. Time for Treatment in Elderly Patients with Acute MI

\section{Door to Needle Time}

Of the 93 cases of ST elevation myocardial infarction, 84 were thrombolysed. Door to needle time was less than 30 minutes in $40(47.62 \%)$ cases. Of the 18 diabetics who were thrombolysed, door to needle time was less than 30 minutes in 8 (44.44\%) patients. There was no significant difference of door to needle time in diabetic and non-diabetic patients ( $p$ value $=0.76$ ).

\begin{tabular}{|c|c|c|}
\hline \multirow{2}{*}{} & \multicolumn{2}{|c|}{ Door to Needle Time } \\
\cline { 2 - 3 } & $\mathbf{3 0}$ Minutes & $\mathbf{3} \mathbf{3 0}$ Minutes \\
\hline Diabetic & 8 & 10 \\
\hline Non-Diabetic & 32 & 34 \\
\hline \multicolumn{2}{|c|}{ Table 5. Door to Needle Time in Elderly Patients with } \\
Acute MI \\
\hline
\end{tabular}

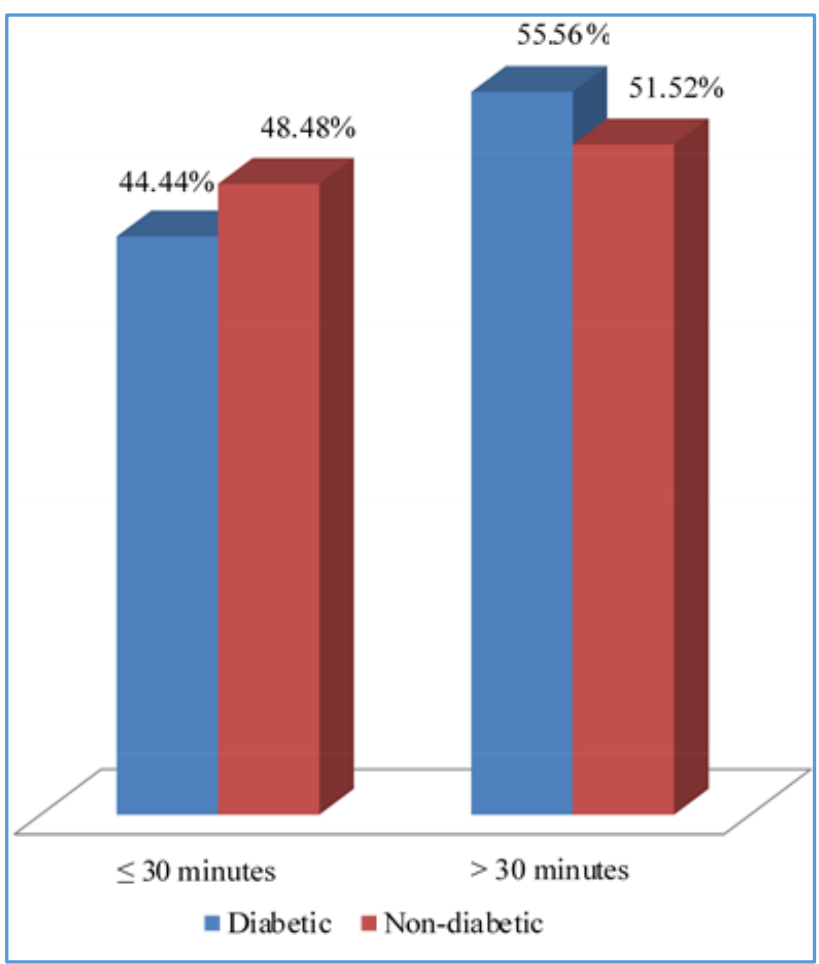

Chart 4. Door to Needle Time in Elderly Patients with Acute MI

\section{Killip Class}

$73(73 \%)$ patients presented in Killip class 1.20 (20\%) had Killip class 2 at admission. Five (5\%) and two (2\%) patients had Killip classes 3 and 4 at admission, respectively.

\begin{tabular}{|c|c|c|c|c|}
\hline $\begin{array}{c}\text { Killip } \\
\text { Class }\end{array}$ & Frequency & Percent & $\begin{array}{c}\text { 95\% CI } \\
\text { Lower }\end{array}$ & $\begin{array}{c}\text { 95\% CI } \\
\text { Upper }\end{array}$ \\
\hline 1 & 73 & $73.00 \%$ & $63.20 \%$ & $81.39 \%$ \\
\hline 2 & 20 & $20.00 \%$ & $12.67 \%$ & $29.18 \%$ \\
\hline 3 & 5 & $5.00 \%$ & $1.64 \%$ & $11.28 \%$ \\
\hline 4 & 2 & $2.00 \%$ & $0.24 \%$ & $7.04 \%$ \\
\hline Table 6. Killip Class at admission in Elderly Patients with \\
Acute MI \\
\hline
\end{tabular}




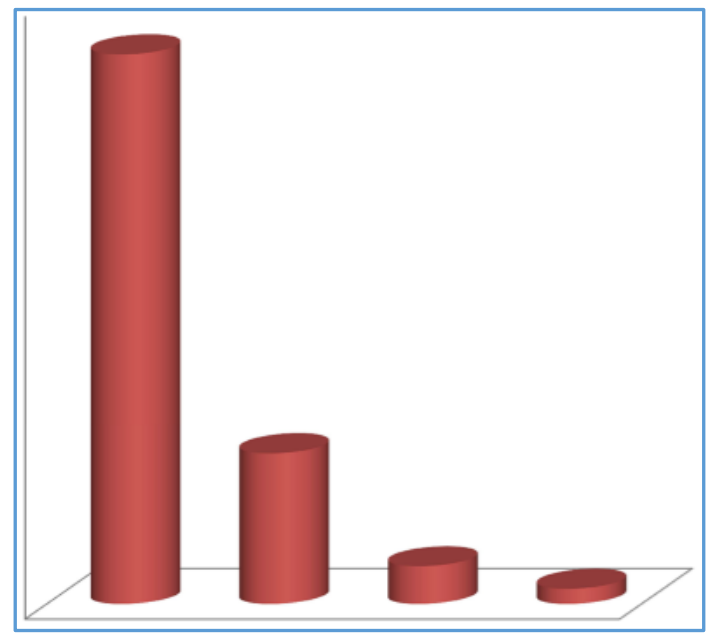

Chart 5. Killip Class at admission in Elderly Patients with Acute MI

\section{Mortality}

The in-hospital mortality was $25 \%(n=25)$. Patients were telephonically followed up regarding the 30-day mortality. Of the 100 patients studied, contact details were available for 68. Of these, 14 patients died before discharge. Of the surviving 54 patients, 16 were lost for follow-up. Of the 38 patients contacted, 2 had died during the period.

\section{Diabetes and In-Hospital Mortality}

In-hospital mortality of diabetic patients was 10 (41.67\%). That of non-diabetics was 15 (19.74\%). There was a significant difference between the two groups. (Odds Ratio $2.9048,95 \%$ CI 1.0807 - 7.8077, $\mathrm{p}=0.03$ ).

\begin{tabular}{|c|c|c|}
\hline & In-Hospital Non-Survivors & $\begin{array}{c}\text { In-Hospital } \\
\text { Survivors }\end{array}$ \\
\hline Diabetic & 10 & 14 \\
\hline $\begin{array}{c}\text { Non- } \\
\text { Diabetic }\end{array}$ & 15 & 61 \\
\hline Table 7. In Hospital Mortality of Acute MI in Elderly \\
Diabetics and Non-Diabetics
\end{tabular}

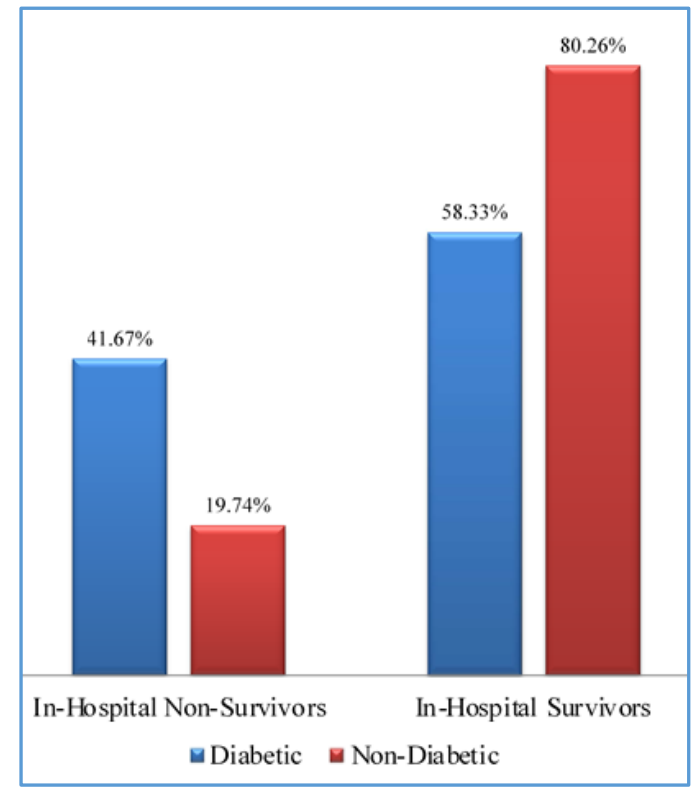

Chart 6. In-Hospital Mortality of Acute MI in Elderly Diabetics and Non-Diabetics
Random Blood Sugar at Admission and In-Hospital Mortality

Data regarding Random Blood Sugar (RBS) at admission was available for 85 patients, of which 23 were diabetic and 62 were non-diabetic. Among non-diabetics in-hospital mortality in patients with RBS $<200 \mathrm{mg} / \mathrm{dL}$ was 9 (17.65\%). In patients with RBS $\geq 200 \mathrm{mg} / \mathrm{dL}$, in-hospital mortality was $2(18.18 \%)$. There was no significant association between RBS at admission and in-hospital mortality in this group ( $\mathrm{p}=$ 1.00). Of the diabetics, $3(30.00 \%)$ non-survivors had RBS $<200 \mathrm{mg} / \mathrm{dL}$. While 7 (53.85) of them had RBS $\geq 200 \mathrm{mg} / \mathrm{dL}$. The difference between the two groups was not significant $(\mathrm{p}=0.40)$.

\begin{tabular}{|c|c|c|}
\hline & Non-Survivors & Survivors \\
\hline RBS $<200$ & 3 & 7 \\
\hline RBS $\geq 200$ & 7 & 6 \\
\hline \multicolumn{2}{|c|}{ Table 8. RBS at admission and In-Hospital Mortality in } \\
Elderly Diabetics with Acute MI \\
\hline
\end{tabular}

\begin{tabular}{|c|c|c|}
\hline & Non-Survivors & Survivors \\
\hline $\mathrm{RBS}<200$ & 9 & 42 \\
\hline $\mathrm{RBS} \geq 200$ & 2 & 9 \\
\hline \multicolumn{3}{|c|}{ Table 9. RBS at admission and In-Hospital Mortality in } \\
Elderly Non-Diabetics with Acute MI
\end{tabular}

\section{TIMI Score and In-Hospital Mortality}

TIMI score was calculated at admission for all patients. Among the non-diabetic patients, in-hospital mortality was 4 (26.67\%) in those with TIMI score $\leq 4$. In-hospital mortality was $11(73.33 \%)$ with TIMI score $>4$. Difference between the two groups was not significant $(\mathrm{p}=0.09)$. Among the diabetic patients, in-hospital mortality was $2(20.00 \%)$ in those with TIMI score $\leq 4$. In-hospital mortality was $8(80.00 \%)$ with TIMI score $>4$. Difference between the two groups was not significant $(\mathrm{p}=0.24)$.

\begin{tabular}{|c|c|c|}
\hline & $\begin{array}{c}\text { In-Hospital } \\
\text { Mortality Present }\end{array}$ & $\begin{array}{c}\text { In-Hospital } \\
\text { Mortality Absent }\end{array}$ \\
\hline TIMI score $\leq 4$ & 4 & 31 \\
\hline TIMI score $>4$ & 11 & 30 \\
\hline Table 10, ThI & & . \\
\hline
\end{tabular}

Table 10. TIMI Score and In-Hospital Mortality of Acute MI in Elderly Non-Diabetics

\begin{tabular}{|c|c|c|}
\hline & $\begin{array}{c}\text { In-Hospital } \\
\text { Mortality Present }\end{array}$ & $\begin{array}{c}\text { In-Hospital } \\
\text { Mortality Absent }\end{array}$ \\
\hline TIMI score $\leq 4$ & 2 & 6 \\
\hline TIMI score $>4$ & 8 & 8 \\
\hline
\end{tabular}

Table 11. TIMI Score and In-Hospital Mortality of Acute MI in Elderly Diabetics

\section{DISCUSSION}

We studied the influence of Diabetes on short-term mortality in 100 elderly patients with acute myocardial infarction. The mean age of the study population was $70.26 \pm 13.44$ years. Of the study population, $24 \%(n=24)$ were diabetic. $30.56 \%$ $(n=11)$ females and $20.31 \%(n=13)$ males had diabetes. This is consistent with earlier studies, where incidence of diabetes is more with age and with female gender.(7)

Mean age of patients without diabetes was $70.21 \pm 13.44$ years. Mean age of the diabetic population was $70.42 \pm 13.70$ years. Majority of the patients (91\%) were between $60-80$ years of age. 64 patients were males and 36 females. 
Acute myocardial infarction in the elderly most commonly involved the inferior and anterior walls in both diabetic and non-diabetic patients. Majority of the patients presented in Killip class 1 . This is comparable to the findings of previous studies.

In our study, majority of the patients sought treatment within 4 hours of onset of symptoms. This is in sharp contrast to the findings of CREATE Study.(4) This can probably be explained by the better access to transportation and healthcare facilities at present in Tamilnadu. Greater awareness of the symptoms of myocardial infarction may also contribute to this observation.

Door to needle time was calculated for the patients who underwent thrombolysis. More than half the patients had a door to needle time $>30$ minutes. This was not significantly different for diabetics. One of the probable reasons for this delay would be the unwillingness of the bystanders to consent for thrombolysis once the risks were fully explained.

In-hospital mortality was $25 \%(n=25)$ in the study population, which corresponds to the previous studies. Of the surviving 75 patients, we contacted 38 patients regarding the 30-day mortality. Of those contacted, 2 had expired over the period (day 8 to day 30).(8)

TIMI score was not a significant predictor of in-hospital mortality in elderly diabetics and non-diabetics. The score was calculated at admission. This fails to take into account any worsening that could have occurred during the hospital stay. This may be a probable explanation for the difference from previous studies.(9) Diabetes mellitus was a significant predictor of in-hospital mortality in the elderly. This corresponds to the findings of previous studies.

\section{Summary}

This was an observational cross-sectional study of the shortterm mortality of acute myocardial infarction in elderly diabetics and non-diabetics. 100 patients were included in the study. 24 patients were diabetic and 76 non-diabetic. The mean age of diabetics was $70.21 \pm 13.44$ years and that of non-diabetics was $70.42 \pm 13.70$ years.

\section{The Salient Findings of the Study were-}

- In-hospital mortality of acute myocardial infarction in the elderly was $25 \%$.

- $\quad$ Elderly patients with acute myocardial infarction had a significantly increased chance of in-hospital mortality if they were diabetic.

\section{CONCLUSION}

Elderly diabetic patients with acute myocardial infarction had a significantly higher in-hospital mortality as compared to elderly non-diabetics.

\section{REFERENCES}

[1] Gupta R. Recent trends in coronary heart disease epidemiology in India. Indian Heart Journal 2008;60:(2 Suppl B):B4-18. Epub 2009/04/22.

[2] Trichon BH, Roe MT. Acute coronary syndromes and diabetes mellitus. Diabetes \& Vascular Disease Research: Official Journal of the International Society of Diabetes and Vascular Disease 2004;1(1):23-32. Epub 2005/11/25.

[3] Krumholz HM. The clinical challenges of myocardial infarction in the elderly. The Western Journal of Medicine 1989;151(3):304-10. Epub1989/09/01.

[4] Xavier D, Pais P, Devereaux PJ, et al. Treatment and outcomes of acute coronary syndromes in India (CREATE): a prospective analysis of registry data. Lancet 2008;371(9622):1435-42. Epub2008/04/29.

[5] Thygesen K, Alpert JS, White HD, et al. Universal definition of myocardial infarction. European Heart Journal 2007;28(20):2525-38. Epub 2007/10/24.

[6] American Diabetes Association. Diagnosis and classification of diabetes mellitus. Diabetes Care 2004;27 Suppl 1:S5-S10.

[7] McGuire DK, Emanuelsson H, Granger CB, et al. Influence of diabetes mellitus on clinical outcomes across the spectrum of acute coronary syndromes. Findings from the GUSTO-IIb study. GUSTO IIb Investigators. European Heart Journal 2000;21(21):1750-8. Epub 2000/10/29.

[8] Misiriya KJ, Sudhayakumar N, Khadar SA, et al. The clinical spectrum of acute coronary syndromes: experience from a major center in Kerala. The Journal of the Association of Physicians of India 2009;57:37783. Epub 2009/07/29.

[9] Woon VC, Lim KH. Acute myocardial infarction in the elderly--the differences compared with the young. Singapore Medical Journal 2003;44(8):414-8. Epub 2004/01/01. 